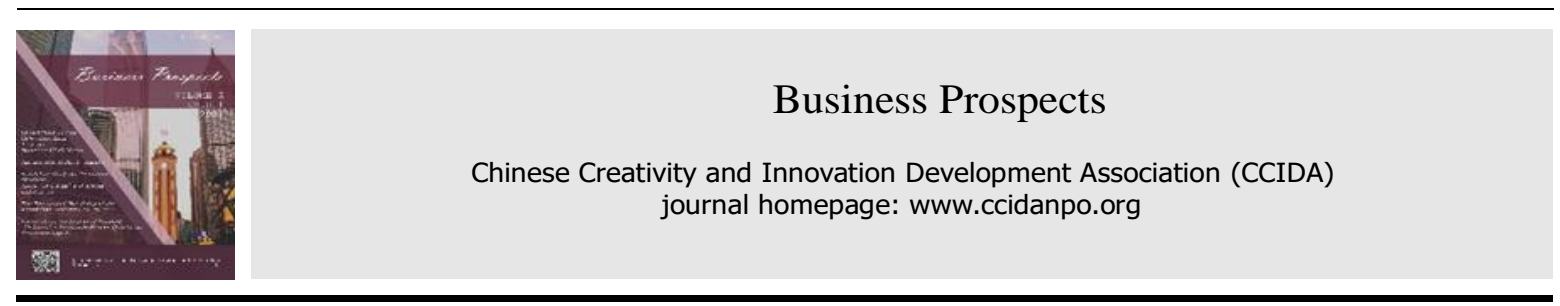

https://doi.org/10.52288/bp.27089851.2021.06.11

\title{
How Teacher Comments Influence Students' Motivation for Writing
}

\author{
Yan-Qing Fang 1 , * \\ ${ }^{1}$ Associate Professor of School of the English Language and Culture, Xiamen University Tan Kah Kee College \\ * Correspondence: 247682022@qq.com
}

Received: 2021.04.05; Accepted: 2021.04.15; Published: 2021.06.01

\begin{abstract}
Developing students' writing ability is known as one of the major goals to be achieved in English teaching and teacher comments are an essential aspect of the English writing course. According to socialcognitive theory, people's self-efficacy beliefs in their skills and ability to complete tasks influence their motivation. However, there is an inconclusive discussion about the effectiveness of teacher comments on student essays in L1 classrooms; and there is an obvious lack of research about the effects of teacher comments on the motivation of EFL students for writing. Primary data for this study are the subject students' answers to questionnaires, their responses in the interviews, their essays, and the teachers' written comments on the students' essays. The researcher finds out that the teacher should affix much attention to their immediate comments, both written and verbal, which can affect writing apprehension and students' self-efficacy beliefs toward writing.
\end{abstract}

Keywords: Teachers' Comments; Social-cognitive Theory; Students' Motivation

\section{Introduction}

Developing students' writing ability is known as one of the major goals to be achieved in English teaching and teachers' comments are an essential aspect of the English writing course. This is especially true nowadays with the predominance of the process approach to writing, which requires some kind of second party feedback, usually from the instructor, on student drafts. Kroll (2001) points out the dependence of current writing instruction on teacher feedback. The driving force behind the essay stemmed from an interest in how to provide more effective and relevant feedback to students. With this in view, much fruitful research into this field is inevitably needed and the recent years have gladly witnessed an increasing interest in it, both at home and abroad.

According to social-cognitive theory, people's self-efficacy beliefs in their skills and ability to complete tasks influence their motivation. Feedback can affect both self-efficacy and writing apprehension in research suggests. Instructor comments, both written and verbal, can affect writing apprehension and students' selfefficacy beliefs toward writing. As Flower and Hayes (1981) noted, writing is a goal-directed process, and setting and meeting goals is an outcome that can motivate.

The researcher reviews the pertinent literature on the practice of teacher commenting and also on the broader issue of student attitude. In earlier studies, Clark (1969) contends that a mixture of criticisms and praise, with raise dominating, produces the most satisfied and confident writers. In recent studies, Marzano and Arthur (1977) concluded that different types of teachers' comments produce about the same improvement in student writing ability. Bata (1972) found no significant differences between marginal and summary comments. Sommers (1982) found those teachers' interlinear comments and marginal comments demand very contradictory revising tasks from students. Ziv (1984) made the following hypotheses to aid the writing instructor: 1) students who are experienced revisers will improve on the structural and conceptual levels if they receive explicit cues about how to revise papers; 2) students who are inexperienced revisers will improve on the lexical and sentential levels if they receive explicit cues about how to revise their papers on these levels. 
The researcher argues that "student motivation" must be carefully defined in order to provide another - if not better - method of measuring the comments that teachers spend so much time making.

This thorough review draws a conclusion that much attention has been paid to teacher comments on student essays in L1 writing classrooms. However, it also shows: 1) there is an inconclusive discussion about the effectiveness of teacher comments on student essays in L1 classrooms; 2) there is an obvious lack of research about the effects of teacher comments on the motivation of EFL students for writing. Therefore, this essay is intended to shed its new light on this field. It is expected that the study will provide some useful hints at how to comment student writings, which will be welcomed by the teachers of the EFL writing course, and consequently, it will show a new insight into the teaching of this course so that the improvement of students' writing ability is predictable.

In view of this, this study seeks to address the following question: How do teachers' comments influence or change the motivation of three different types of students (students who are highly-motivated, motivated, and non-motivated) in EFL composition classes? Thus the present research is designed to find an answer to this question.

Based on the various researches on teacher comments, the researcher hypothesizes that teacher comments in general influence students' writing motivation, and that positive reader responses motivate all students for English writing more than other types of feedback, for example, teacher corrections. The researcher similarly hypothesizes that constructive summary comments are more motivational to all students than purely negative or purely positive comments, as Clark (1969) found. Based on the data collected from the survey and the students' essays, and according to the responses obtained in the interviews with the students, both of these assumptions need to be reassessed through the study.

\section{Methodology}

\subsection{The Research Question}

This study seeks to address the following question:

How do teachers' comments influence or change students' motivations for writing?

\subsection{Setting and Participants}

As Murray (1978) and Ziv (1984) both pointed out, many experimental studies in composition research have yielded inconclusive results. In this investigation, the researcher used the case-study method at College of Foreign Languages and Cultures in Xiamen University (referred to XMU hereafter) during the autumn semester of 2007 to obtain data from students via questionnaires and interviews, in order to define motivation levels and speculate about motivation changes elicited by teacher comments. The study lasted one semester and the qualitative approach was applied in the study with the help of instruments including questionnaires, interviews and student essays.

The students involved in this study were taking a basic writing course. This compulsory course, aimed to help students to develop English writing skills and ability, is set for the second- and third-year English majors in College of Foreign Languages and Cultures in XMU. The course provides for two hours of lectures each week throughout two 16-week terms. Students were assigned different types of writing: description, narration, exposition and argumentation. They wrote journals, guided writings and free writings, and each teacher sometimes responded with written comments. Students received comments and grades on the drafts they handed in, and were then told that at no time would their names be used to identify them in any reports or other documents.

Primary data for this study are the subject students' answers to questionnaires, their responses in the interviews, their essays, and the teachers' written comments on the students' essays.

\section{Procedures}

The research took place over the autumn semester of 2007 in seven classes of 238 students, with a majority of females and a minority of males (This is the usual case of Foreign Languages School). At the beginning of the semester, the researcher asked the 238 English majors, who were taking the English writing course in their second year of study, to respond to a preliminary questionnaire designed by the researcher. [See Appendix A for the questions asked in the preliminary questionnaire.] The researcher visited each class and administered 
the original survey before any graded essays had been returned to the students. In one class, though, students had received diagnostic comments on one preliminary essay and some had had conferences with the instructor. This original survey was conducted in order to establish a baseline of motivation toward writing - to define and categorize subjects as "not-motivated," "motivated," and "highly motivated." These categories were defined based on: 1) a student's reason for taking the English writing course; 2) how often the student writes in English outside of class; and 3) how the student rates his or her own English writing skills. These criteria were chosen because they are good dictators of motivation, and they are fairly easy to measure. These classifications will be expanded on below.

The researcher closely examined three of the thirteen questions listed in the preliminary questionnaire in order to create three sub-levels of motivation. The criteria for defining motivation levels and the rationale for making these choices are outlined below: [Also see Appendix B for the criteria used for establishing motivation groups]

\subsection{For a Subject to be Considered “Highly Motivated (referred to as HM hereafter)," He or She Responded in the Following Manner:}

Question \#4: “Would you be taking this English writing course if it were not required?" The student answered, "Yes." The empirical experience of the researcher tells her that students who lack motivation take English writing courses in order to meet general education requirements. The researcher speculates that students who are highly motivated to write take the English writing course because they want to, and not because it is required.

Question \#6: "How often do you write in English outside of class (except the required writing assignments given by the instructors)-say, in a journal/diary, letters to a friend, on the Internet, to practice English or simply for pleasure?" The student answered "frequently," or "very frequently." The researcher assumes here that students who are highly motivated to write in English compose almost once per week or at least once every two weeks.

Question \#9: "How would you rate your current English writing skills?" The student answered "very good," or "excellent." The researcher speculates that motivated students are fairly confident about their ability to write. To narrow the pool of subjects, the researcher chose to limit the HM category to those who felt that their abilities were better than "good."

\subsection{For a Subject to Be Considered "Motivated (referred to as M hereafter)," He or She Responded in the Following Manner:}

Question \#4: The student answered, "Yes." The researcher assumes that a motivated student will take the English writing course because she wants to, and not because it is required.

Question \#6: The student answered “occasionally," or "frequently." The researcher speculates that a motivated student will write once every two weeks or at least once per month.

Question \#9: The student answered "fair," "good," or "very good.” The researcher believes a motivated student feels fairly confident about his or her ability to write, yet perhaps not as confident as the highlymotivated student.

\subsection{For a Subject to Be She or He Responded Considered "Non-motivated (referred to NM hereafter)," She or He Responded in the Following Manner:}

Question \#4: The student answered "No." The researcher speculates that the student who lacks the motivation to write will not take a writing course unless it is required for his or her major course of study.

Question \#6: The student answered "seldom," or even less often. The researcher assumes that a NM student writes only as often as it is required in college, or as it is necessary in part-time jobs.

Question \#9: The student answered "fair," "poor" or "very poor." While the researcher believes that being unmotivated does not always determine writing ability, she assumes, here, that non-motivated students do not perceive their writing skills to be better than "fair."

In order to select subjects in the case study, the researcher also examined answers to Question 7 ("How do 
you feel when your writing is going to be read or evaluated by another student?") and Question 8 ("How do you feel when your writing is going to be read or evaluated by your instructor?"). Since these are free-response questions, the researcher subjectively looked for a range of positive and negative responses in order to obtain a representative sample of participants. After students were initially classified into one of the three groups based on the above criteria, the researcher roughly examined these questions in order $t$ to narrow the number from 238 to 12 subjects. It should also be noted that all the selected subjects in the study have pseudonyms.

During the same period, the researcher had already looked through all 238 of the students' first assigned papers in advance and had already examined the actual marks of the instructors, assessing them with a combination of Ziv's classification system (implicit vs. explicit), and the researcher's own. After a careful study of the written comments, the researcher found more implicit cues than either explicit cues or teacher corrections; the researcher also found other marks that she has termed as "positive reader-response cues" (marks which indicate that a teacher is responding as a reader).

The researcher soon selected four students from each motivation category to be interviewed on two or three different occasions, so as to further discuss their essays and their attitudes toward the comments themselves. The researcher contacted these students by telephone and then in person. During the scheduled interviews, the researcher asked subjects if they considered themselves motivated, non-motivated, or highlymotivated for English writing. Their answers, 9 times out of 12 times, matched the researcher's prior assessment (based on their answers to the survey questions).

The following are the questions asked during the interviews:

1) What do you like and/or dislike about writing?

2) How do you perceive the class atmosphere and/or the teacher's personality?

3) How do you perceive yourself as a writer (highly motivated, motivated, or not motivated)? Please elaborate.

4) What is good writing? Are you capable of it?

Each subject filled out the attitude questionnaire before she or he had received any comments from the teacher (students in one class had received only diagnostic comments from the instructor, though). After they received their commented essays, the researcher was able to ask the subjects which comments motivated them for writing by conducting further interviews. Nearly every subject also brought an additional piece of writing with him or her to be discussed during the later interviews in the following three months.

The following questions were asked about the specific comments:

1) How did that comment make you feel?

2) How did you use this comment (i.e. for revision)?

3) What did your instructor mean by that comment?

4) Is there enough direction in this comment?

5) What is your overall impression of the summary comment?

6) How would your own comment, if you were the teacher, be different?

7) Does your teacher invite you to write any self-evaluative comment before you hand in your paper? If so, tell me about it.

8) Do these comments affect your attitude; do they motivate you? If so, tell me how.

In the interviews, the researcher allowed students to respond as freely and discursively as they desired in order to clarify and enhance questionnaire responses. These responses were recorded in detail and later analyzed. One extraneous variable - which in fact did become a dependent variable - was how the students felt about the classroom atmosphere and the teacher. The researcher ever hypothesized that a student who perceives the classroom as friendly or cordial would have a different attitude toward teachers' comments than a student who perceives the classroom atmosphere as rigid or even hostile. This hypothesis, as well as the other data collected, will be examined at length in the Discussion section.

A final questionnaire was designed around the middle of the semester. Again, the researcher operationally defined motivation (HM, M, NM) according to: 1) the student's reason for taking the English writing course; 2) how often the student writes in English outside of class; and 3) how the student rates her or his own English 
writing skills. To say that a student has demonstrated a change in motivation is to show that the student has moved from one of the three levels of motivation to another. [See Appendix $\mathrm{C}$ for the questions asked in the final questionnaire.]

It is important to note that, though the researcher was not conducting an actual experiment, she did use a scientific design as closely as possible. Thus, the final questionnaire was given to the twelve subjects interviewed as well as a control group of twelve subjects that the researcher never actually had conversations with. This was done to compare the survey responses of the case-study students with those of the non-case study students to determine if the researcher, a person who appeared unusually concerned about students' writing, had any effect on the students' answers. The final questionnaire was delivered to the students during the 12th week of the Autumn 2019 semester. (To avoid the influence of the final exams, the researcher did not conduct that survey at the very end of the semester.)

\section{Conclusion}

Writing skills play important roles in students' daily lives and academic study, therefore, the research on how teachers' comments influence students writing skill counts. Based on the questionnaires collected, the researcher find out that teachers' comments in general influence students' writing motivation, and that positive reader responses motivate all students for English writing more than other types of feedback, for example, teacher corrections. The researcher similarly finds that constructive summary comments are more motivational to all students than purely negative or purely positive comments, as Clark (1969) found. Therefore, the teacher should affix much attention to their immediate comments, both written and verbal, which can affect writing apprehension and students' self-efficacy beliefs toward writing.

\section{Appendix A. The Preliminary Questionnaire}

Dear student:

You are invited to participate this semester in a study about instructor feedback and students' motivation for writing in English. Your participation in the research will help provide information that could improve instruction in English writing courses at Xiamen University and other campuses.

As part of the study, you will be asked to complete a survey. Your identity will be held in confidence during the study, and you will remain anonymous in any subsequent report about the results of the study. Your grade will not be affected whether you agree to participate or not. Participation in the study is voluntary. If at any time during the study, you choose to withdraw, your request will be honored. The study presents no foreseeable physical or psychological risks to you.

If you kindly agree to participate in the study, please answer the following questions openly and honestly.

1. What do you like most about English writing?

2. What do you dislike the most about English writing?

3. What sort of English writing have you done?
dairies/journals
letters
essays short stories
poems
applications
essay exams
other(please name)

4. Would you be taking this English writing course if it were not required? Yes No

5. What do you believe is the ideal learning stage to take the English writing course during the four-year study? and why?

6. How often do you write in English outside of class (except the required writing assignments given by the instructors) - say, in a journal/diary, letters to a friend, on the Internet, to practice English or simply for pleasure?

Very frequently (once per week)

Frequently (once every two weeks)

Occasionally (once per month)

Seldom (once or twice every 3 to 6 months)

Rarely (once per year)

Never

What type of writing? (see question \#3)

7. How do you feel when your writing in English is going to be read or evaluated by another student? 
8. How do you feel when your writing in English is going to be read or evaluated by your instructor?

9. How would you rate your current English writing skills?
Excellent
Very good
Good
Fair/Ok
Poor
Very poor

10. How helpful are the things you are learning about English writing now in other courses you are taking now? Very helpful___ Moderately helpful___ Slightly helpful___ Not very helpful

11. How helpful do you think the things you are learning about English writing now will be in your job after you leave the University?

Very helpful___ Moderately helpful___ Slightly helpful____ Not very helpful

12. What, in your opinion, is good English writing?

13. Would you be willing to answer more questions at a later date to contribute to this study?

Yes

No

Appendix B. Criteria Used for Establishing Motivation Groups

\begin{tabular}{|c|c|c|c|}
\hline Question & $\begin{array}{l}\text { HM Group } \\
\text { Responses }\end{array}$ & $\begin{array}{l}\text { M Group } \\
\text { Responses }\end{array}$ & $\begin{array}{l}\text { NM Group } \\
\text { Responses }\end{array}$ \\
\hline $\begin{array}{l}\text { \#4 Would you be taking this English writing course } \\
\text { if it were not requires? }\end{array}$ & Yes & Yes & No \\
\hline $\begin{array}{l}\text { \#6 How often do you write in English outside of } \\
\text { class (except the required writing assignments } \\
\text { given by the instructors) - say, in a journal/ } \\
\text { diary, letters to a friend, on the Internet, to } \\
\text { practice English or simply for pleasure? }\end{array}$ & $\begin{array}{l}\text { Very frequently } \\
\text { or frequently }\end{array}$ & $\begin{array}{l}\text { Occasionally or } \\
\text { frequently }\end{array}$ & $\begin{array}{c}\text { Occasionally, } \\
\text { seldom, rarely, } \\
\text { or never }\end{array}$ \\
\hline $\begin{array}{l}\text { \#9 How would you rate your current English } \\
\text { writing skills? }\end{array}$ & $\begin{array}{l}\text { Excellent or } \\
\text { very good }\end{array}$ & $\begin{array}{l}\text { Fair, good, or } \\
\text { very good }\end{array}$ & $\begin{array}{l}\text { Fair, poor, or } \\
\text { very poor }\end{array}$ \\
\hline
\end{tabular}

\section{Appendix C. The Final Questionnaire}

Dear student:

Thank you for agreeing to participate this semester in this study about instructor feedback and students' motivation for writing in English. Your participation in the research will help provide information that could improve instruction in English writing courses at Xiamen University and other campuses. As part of the study, you will be asked to complete this survey. Your identity will be held in confidence during the study, and you will remain anonymous in any subsequent report about the results of the study.

Please answer the following questions openly and honestly.

1. Would you be taking this writing course if it were not required?

Yes__ No

2. How often do you write in English outside of class (except the required writing assignments given by the instructors) - say, in a journal/diary, letters to a friend, on the Internet, to practice English or simply for pleasure?

Very frequently (once per week)

Frequently (once every two weeks)

Occasionally (once per month)

Seldom (once or twice every 3 to 6 months)

Rarely (once per year)

Never

What type of writing?

3. How do you feel when your writing is going to be read or evaluated by your teacher or a fellow student?

4. How would you rate your current writing skills?

Excellent_ Very good_ Good

Fair/Ok Poor

Very poor

5. How helpful are the things you learned about writing in this class? Very helpful Moderately helpful Slightly helpful

Not very helpful

6. How much of an impact has each of the following had on your attitude toward writing this semester $(5=$ greatly impacted, $3=$ impacted, $1=$ no impact)? 
Class lectures

Comments by the teacher on graded papers

Feedback from your fellow students

Conferences with your teacher

Talking about your writing with other instructors (if applicable)

Writing in a journal/diary

7. What is your attitude toward writing? Please elaborate on the back of this sheet mentioning what you feel has influenced your attitude the most.

\section{References}

1. Bata, E. J. (1972). A Study of the Relative Effectiveness of Marking Techniques on Junior College Freshman English Composition (Unpublished Doctoral Dissertation). University Maryland, MD, 34: 62-A.

2. Clark, G. A. (1969). Interpreting the Penciled Scrawl: A Problem in Teacher Theme Education (Unpublished Doctoral Dissertation). University of Chicago, IL: ERIC Document Reproduction No. ED 039-241.

3. Flower, L. S., and Hayes, J. R. (1981). A Cognitive Process Theory. College Composition and Communication, 32 : 365-387.

4. Kroll, B. (2001). Considerations for Teaching an ESL/EFL Writing Course. In Celce-Murcia, M. (eds.) Teaching as a Second or Foreign Language ( $3^{\text {rd }}$ ed.), 219-232.

5. Marzano, R., \& Arthur, S. (1977). Teacher Comments on Student Essays: It doesn't Matter What You Write (Unpublished Manuscript). University of Colorado, CO, ERIC Reproduction Number 147- 864.

6. Murray, D. M. (1978). Internal Revision: A Process of Discovery. In Cooper, C. R., \& Odell, L. (eds.) Research on Composing: Points of Departure. Urbana, IL: National Council of Teachers of English.

7. Sommers, N. (1999). Responding to Student Writing. In Straub, R. (eds.) A Sourcebook for Responding to Student Writing, Cresskill: Hampton Press Inc., 107-117.

8. Ziv, N. D. (1984). The Effect of Teacher Comments on the Writing of Four College Freshman. In Beach, R., \& Bridwell, L. S. (eds.) New Directions in Composition Research, 362-380.

(Editors: Airtok Lin \& Luyao Wu) 